\title{
Marrying Hydrological Modelling and Integrated Assessment for the needs of Water Resource Management
}

\author{
B. F. W. CROKE ${ }^{1,2}$, R. S. BLAKERS ${ }^{1,2}$, S. EL SAWAH ${ }^{1}$, B. FU ${ }^{1}$, \\ J. H. A. GUILLAUME ${ }^{1}$, R. A. KELLY ${ }^{1}$, M. J. PATRICK ${ }^{1}$, A. ROSS ${ }^{1}$, \\ J. TICEHURST ${ }^{1}$, R. BARTHEL ${ }^{3}$ \& A. J. JAKEMAN ${ }^{1}$ \\ 1 National Centre for Groundwater Research and Training, Fenner School of Environment and Society, \\ Australian National University, Canberra, Australia \\ barry.croke@anu.edu.au \\ 2 Mathematical Sciences Institute, Australian National University, Canberra, Australia \\ 3 Department of Earth Sciences, University of Gothenburg, Sweden
}

\begin{abstract}
This paper discusses the integration of hydrology with other disciplines using an Integrated Assessment (IA) and modelling approach to the management and allocation of water resources. Recent developments in the field of socio-hydrology aim to develop stronger relationships between hydrology and the human dimensions of Water Resource Management (WRM). This should build on an existing wealth of knowledge and experience of coupled human-water systems. To further strengthen this relationship and contribute to this broad body of knowledge, we propose a strong and durable "marriage" between IA and hydrology. The foundation of this marriage requires engagement with appropriate concepts, model structures, scales of analyses, performance evaluation and communication - and the associated tools and models that are needed for pragmatic deployment or operation. To gain insight into how this can be achieved, an IA case study in water allocation in the Lower Namoi catchment, NSW, Australia is presented.
\end{abstract}

Key words integrated assessment; integrated modelling; hydrology; social science; interdisciplinary; water resource management; Australia

\section{INTRODUCTION}

Water Resource Management (WRM) is recognised as a grand challenge or "global problematique" due to increasing and competing demands on the world's water and connected land resources and the complex nature of its governance. Ongoing management and resolution of WRM issues requires advances in the way natural sciences and social sciences support decision making. The recognition of the need for interdisciplinary research and management approaches has created the beginnings of many conceptual bridges originating from many different disciplines in the WRM field. Hydrology is one such discipline where the demand for water security for human needs has shaped the application and research agenda of the discipline. The current scientific decade of the International Association of Hydrological Sciences (Panta Rhei) (Montanari et al. 2013) will have a strong focus on human-water interactions (e.g. the call for research in the field of socio-hydrology by Sivapalan et al. 2012). There is a wealth of knowledge and experience in understanding and treating interdisciplinary water resource issues, but completion of the conceptual bridges between relevant disciplines is needed in order to progress integration further and improve the efficacy of WRM. Integrated Assessment (IA) provides one such mechanism and repository of knowledge and maturing practice (e.g. Giupponi et al., 2006).

The aim of this paper is to highlight opportunities for further research on how hydrology can contribute to IA, providing possible foci for the Panta Rhei decade. The paper describes the conceptual bridges and practical links between IA and hydrology, with the purpose of contributing empirical evidence to support the imperative for continuing human-water systems science, and to illustrate that IA can provide a pragmatic approach to the management of complex human-water management issues. The paper discusses why IA is needed, and the role of hydrology in IA, using a case study in the Namoi basin, Australia. This builds on previous work in Thailand, linking biophysical, household decision and socio-economic models that operate across different spatial and temporal scales. See Letcher et al. (2006a,b) for an exposition and detailed results from applying integrated assessment and modelling. 


\section{THE IMPERATIVE FOR INTEGRATED ASSESSMENT (IA)}

In this paper we utilise the term Water Resource Management (WRM) with an understanding that it is a component of the broader concept of water governance. Water governance encompasses the totality of structures, processes and arrangements put in place to "manage the delivery of water services at different levels of the society" (Rogers \& Hall, 2003). Coping with complex water issues under an uncertain future requires adaptive governance systems that have the capacity to incorporate learning and change in order to avoid threats and seize opportunities (Ison et al., 2014). Although much effort has been channelled into the development of conceptual approaches to deal with the multi-dimensional nature of adaptive governance and complex human-water systems issues (including integrated water management, adaptive water management (Pahl-Wostl et al., 2008, resilience thinking (Folke 2006), hydroeconomic analysis (Harou et al., 2009) and social-ecological analysis (Ostrom 2009), participatory modelling (Hare 2011), and transdisciplinary science (Pohl 2008), there is still a lack of robust, pragmatic methodologies and tools to support these concepts and approaches.

Integrated Assessment (IA) is one interdisciplinary field that has the capacity to clarify the tools and processes that are needed in any given problem situation. Integrated assessment and modelling is becomingly increasingly accepted as a way forward to address complex water issues (see Jakeman and Letcher 2003 for a review; and Giupponi et al, 2006). IA is a procedure that brings together researchers, policy makers and stakeholders to share their views and knowledge in order to improve system understanding, and support decision making (Jakeman et al. 2006). The integrated modelling process and its outputs provide a framework to amalgamate and structure knowledge from multiple scientific disciplines (e.g. hydrology, economics, ecology and social psychology/human behaviour) to develop a multi-disciplinary perspective about the issue being addressed that cannot be derived from mono-disciplinary stances (Jakeman and Letcher 2003). IA promotes transparency where all assumptions and uncertainties (and their implications), including knowledge gaps and contested science, are explicitly recognized and articulated. IA utilises a range of conceptual (e.g. influence diagrams), analytical (e.g. numerical models and risk analysis tools) and participatory methods (e.g. workshops and interviews).

Integrated modelling is a primary tool for IA, and is initiated by defining the modelling scope and context, purpose (prediction, decision making, and/or learning), issue/problem framing, participatory processes and procedures, outputs, and how the modelling serves the existing or new management policy context.

\section{HYDROLOGY IS KEY FOR THE INTEGRATED ASSESSMENT (IA) OF COMPLEX WATER ISSUES}

Water has been termed the bloodstream of the biosphere (Falkenmark 2001) and the functioning of many aquatic ecosystems is recognised as dependent on the "master variable" of streamflow (Poff et al. 1997). Hydrology and hydrological modelling are therefore vital underpinning elements to understanding and managing the water resources upon which humans and ecosystems depend. More specifically they potentially enable the quantification of catchment response to change (depending on ability to capture this), which is key to providing the link to other model components and variables relevant to the problem or issue under investigation.

Hydrology is a well-developed science, providing opportunities to link more purposefully and comprehensively with IA, thereby enhancing the potential of both. It is the role of hydrologists to formulate and evaluate the hydrological model (HM), and through interaction with other disciplines, ensure a holistic conceptualisation of the hydrological system. A coupled human-water systems approach to WRM provides a challenge to hydrological modellers to develop a new research agenda where hydrology meets the needs of WRM in terms of engagement with appropriate concepts, model structures, scales of analyses, performance evaluation and communication - and the associated tools and models that are needed for pragmatic deployment or operation of policy, legislation and regulation. 
IA in general, and Integrated Modelling in particular, provide a useful interface between HMs and the drivers, impacts and responses comprising the broad system components, as well as feedbacks within and between these components. Drivers may be either controllable (e.g. policy options) or uncontrollable (e.g. climate conditions). IA needs to consider the social limits to managing the resource (capacity), as well as the impacts society will have on those resources. This includes direct impacts (e.g. use of water) and indirect impacts (e.g. changes in land use and land management). Furthermore the attitudes, values and behaviours of users and stakeholders play an important role in the responses adopted (be they regulatory or practice based) as well as how feedback to other components or variables within the system operate.

\section{CASE STUDY: THE LOWER NAMOI INTEGRATED MODEL}

This case study describes an IA for groundwater and surface water allocation in the Lower Namoi catchment of New South Wales, Australia (Jakeman et al. 2014). In this example, the purpose of the IA was to work with major stakeholders and landholders in general to develop and share an understanding of the socioeconomic and ecological impacts of climate variations and water policy options, as well as to identify adaptation options by irrigators who are facing further reductions in water allocations. As part of this process, an integrated model was developed to identify and explore the trade-offs between the social, hydrological, economic and ecological impacts of various climate and policy scenarios. Figure 1 illustrates the various components of the integrated model.

The integrated model uses prediction of the natural surface and groundwater flow, and the policy scenarios to estimate the water extraction limits. These are used to determine water use and crop yields given the climate and various crop types. This is then combined with the output from the likely behaviours and adoption of various farming management actions by landholders from the social model, the water allocation levels, and the crop yields and water use, to input into the farm decision model which determines farm profit. It can then calculate the extracted flow and groundwater level remaining following farmer decisions, and estimates the ecological impacts of the remaining available surface and groundwater flows on the ecology. The primary output of the integrated model is a trade-off matrix for a selected set of scenario options. The matrix comprises the likelihood of the adoption of various practices under each scenario, as well as the impacts simulated from each of the integrated model components.

\section{The role of hydrological modelling in the Namoi IA and its key challenges}

This section of the paper presents how the different components of the integrated model challenge the design of the HM component, illustrating how hydrology as a discipline needs to be flexible to accommodate IA and WRM and thus the broader human-water systems thinking.

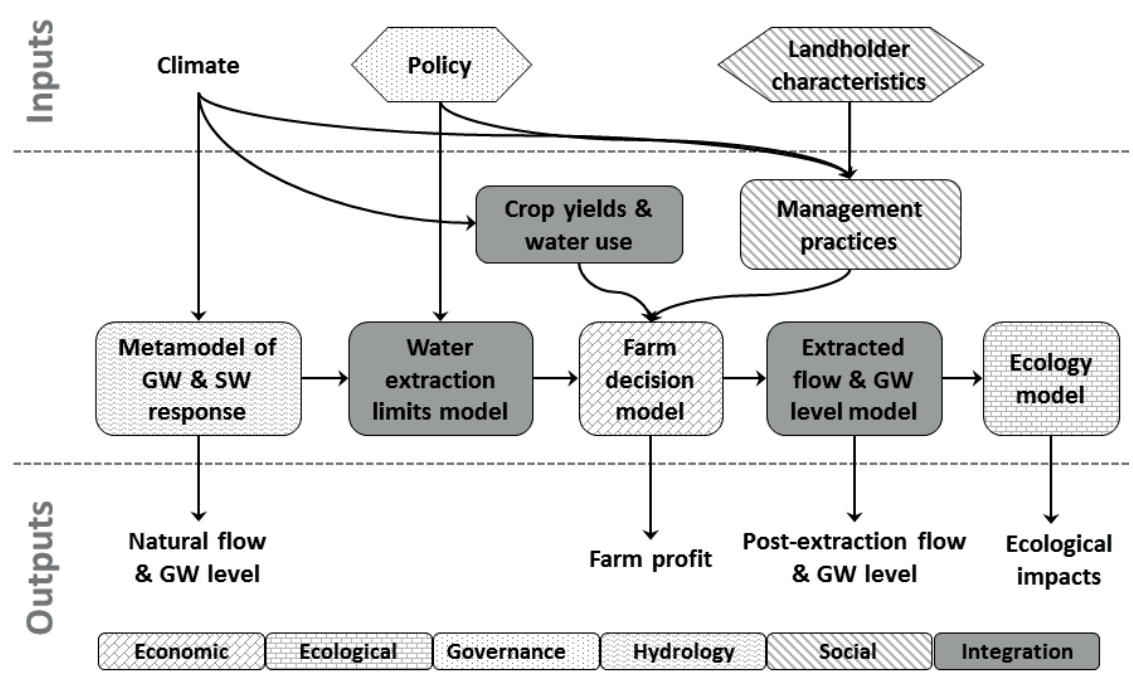

Fig. 1 Schematic overview of the Namoi integrated model (GW: groundwater, SW: surface water). 
The challenge for the HM component presents itself primarily as a need to reconcile the spatial and temporal scales of operation and output of each model component. In other words the needs of the IA determined the style of the HM and the processes and scales it represented. Each component of the model is constrained by the available data, as well as the scales that are suitable for each purpose. Sub-daily time steps are often preferred for HM in order to better capture the hydrological processes. For the Namoi case study however, long-term rainfall data is only available at a daily timestep, constraining the HM to a daily time scale. In addition, the core groundwater data (e.g. groundwater levels, abstractions) were not sufficiently sampled to permit fine spatial and temporal representation within the model. Furthermore, minimum scales for HM discretization were determined by the accuracy required for the outputs (e.g. land management practices and water extraction could not be realistically considered at a resolution finer than zones due to limitations in the available data and privacy considerations). The HM was thus formulated as a 10 zone or subregion-based disaggregation of the Lower Namoi with daily surface-groundwater interactions represented at each lumped zone scale.

For IA, trade-offs need to be made not only between environment and economic benefits/costs, but also between how these benefits/costs play out across different locations. This requires the HM to adequately account for spatial variation in hydrological regimes, demonstrating some of the scale issues that need to be addressed in developing an integrated model. For (ecological asset) sites of interest, the ecological model estimates the suitability of flooding and the groundwater regime to the maintenance and regeneration of riparian vegetation. From the ecological viewpoint, flood impacts need streamflow/water level values on at least a daily time step. The impact of fluctuations in the groundwater level can be represented at a much coarser scale (reflected in the resolution of the groundwater level data that is routinely collected, leading to groundwater modelling being often limited by the available data). Maintenance and regeneration of riparian vegetation is strongly influenced by small- to medium-sized floods, with large floods influencing the broader flood plain (dominated by cropping and grazing). In the case study region, groundwater has an impact on vegetation only if the water table is within about $10 \mathrm{~m}$ of the surface. Thus the calibration of the HM needs to be focused on the daily reproduction of flows near the commence-to-flood level, as well as longer-term fluctuations in the groundwater levels within $10 \mathrm{~m}$ of the surface at specific sites of interest.

More broadly for the IA, the HM is required to address differently the levels of complexity at different scales; at the broader scale where the farm decision and social model are represented, the requirement on the model complexity can be low. However, at a finer scale where the ecological model dominates, the requirement on complexity can be higher. In addition, the HM may require inputs from other model components (e.g. impact of farming decisions on hydrological response through crop evapotranspiration, see Letcher et al. 2006a). Solutions include having a complex model that captures all the processes, or a simpler model that can be calibrated to address different levels of complexity for different IA model components. In the latter case, the role of HM no longer focuses on accurately representing the system at various scales at the same time, but rather its priority is to provide sufficiently accurate inputs to other model components. In either case, the modellers of different components need to work together to ensure the HM captures what other components require. This "marriage" is woven throughout the IA process, and the HM interacts with the other components from the initial scoping, to integrated modelling, to uncertainty analysis, and to refining HM scopes and complexities.

\section{Opportunities for building conceptual bridges: from a hydrology perspective}

The previous case study and others (Letcher et al., 2006a,b) undertaken by the authors provide some valuable lessons. Table 1 provides an overview of the existing hydrological methods, their limitations and potential future research directions that may contribute to the building of conceptual bridges between hydrological modelling and integrated assessment, and between the natural sciences and the social sciences to support decision making in the context of water management and allocation. 
Table 1 Hydrological methods, limitations and some potential future research directions.

\begin{tabular}{|c|c|}
\hline $\begin{array}{l}\text { Contribution of existing } \\
\text { hydrological method }\end{array}$ & $\begin{array}{l}\text { Limitation of existing } \\
\text { hydrological methods }\end{array}$ \\
\hline $\begin{array}{l}\text { 1. Predictions about effect of } \\
\text { selected changes that can be well } \\
\text { understood from existing data, } \\
\text { e.g. effect of pumping on flow. }\end{array}$ & $\begin{array}{l}\text { Uncertainty in future changes in } \\
\text { catchment behaviour under non- } \\
\text { stationarity, unknowns and } \\
\text { surprises. }\end{array}$ \\
\hline
\end{tabular}

2. Much of the current focus on uncertainty in HMs is around rigorous, quite formal methods, e.g. Bayesian Markov Chain Monte Carlo and inverse methods.

The available methods are not necessarily suited to the problems addressed in IA, which need to take into account stakeholder views and non-stationarity.

\section{Conceptual models offer the} facility to explore some policy changes.

4. Basic concepts, e.g. of water cycle are usually well explained.

\section{Scenario-based variation of} inputs, parameters and multiple models provide a solid foundation.

6. Model evaluation allows for comparing model's output with existing data.

7. Distributed and lumped HMs offer techniques for addressing multiple scales.

8. End products of HMs are still largely prediction of time series, though there is increasing calculation of relevant indicators.

More complex policy changes depend on distributed models.

Specific model assumptions can be difficult to justify to users.
Long model development subsequently make additional changes.

Difficult for users to understand and assess model evaluation processes.

Some policies or combinations can only be represented in simplified form.

Not clear how to ensure the outputs of an HM are suitable for impact models etc. timeframes makes it difficult to

Potential research direction

How can model representations of processes that cannot be well identified with existing data be resolved? (e.g. distinguishing effect of change in climate and from land use).

How can analysis of HMs help users approach irreducible and unrecognised uncertainty constructively, rather than treating uncertainty as a weakness to be eliminated? How much exploration of uncertainty is enough from the point of view of policy design?

How can model runs be sped up? e.g. using high performance computing or meta-modelling

How can assumptions of HMs be made more accessible to users, and how can users have a role in evaluation and modification?

How can barriers to explore alternate models of the system be reduced?

How can user's HM evaluation criteria be reconciled with statistical measures, and how can statistical measures be made more accessible to users?

What other techniques can be used to address policy design purposes, and what role can HMs play in them?

How can HMs be evaluated in terms of their ability to predict relevant system indicators for decision support and provide adequate input to impact models?

\section{CONCLUSIONS}

IA and related disciplinary communities have developed many valuable approaches, frameworks and tools for addressing complex, challenging issues in water management at various scales. While there has been considerable progress in this regard, there is still significant scope for more active engagement between researchers, practitioners and policy makers in order to provide legitimate, pragmatic and relevant solutions to these challenges.

Case studies like the one presented can provide a wonderful vehicle to expand and enhance Integrated Assessment (IA) processes and procedures. They provide a focus for hydrologists by presenting tough real-world questions that require the consideration of multidisciplinary perspectives that can in turn only enrich their science. They also present hydrologists with the opportunity to provide rigorous modelling expertise and tools in an area where the multi- 
dimensional complexity of the issues and problems that need to be addressed can be overwhelming for decision-makers.

Hydrologists often have already established strong links to vibrant communities in inter alia ecology, climatology, soil science, global change and remote sensing. A strengthening with the relevant social science communities would further progress integrated assessment and modelling and provide more socially relevant and acceptable decision outcomes for sustainable water resources management.

Acknowledgements This study was funded by the Cotton Research and Development Corporation, and the National Centre for Groundwater Research and Training, an Australian Government initiative supported by the Australian Research Council and the National Water Commission.

\section{REFERENCES}

Antunes, P., et al. (2009) Participation and evaluation for sustainable river basin governance. Ecological Economics 68(4), 931939.

Falkenmark, M. (2001) The greatest water problem: the inability to link environmental security, water security and food security. International Journal of Water Resources Development 17(4), 539-554.

Folke, C. (2006) Resilience: the Emergence of a Perspective for Social-Ecological Systems Analyses, Global Environmental Change 16(3), 253-267.

Giupponi, C., et al. (eds) (2006) Sustainable Management of Water Resources: an Integrated Approach. Edward Elgar Publishing, Cheltenham, UK, 361pp.

Hare, M. (2011) Forms of participatory modelling and its potential for widespread adoption in the water sector. Environmental Policy and Governance 21(6), 386-402.

Harou, J., et al. (2009) Hydro-economic models: concepts, design, applications and future prospects. Hydrology Journal 375(34), 627-643.

Ison, R., Grant, A. and Bawden, R. (2014) Scenario praxis for systemic and adaptive governance: A critical framework. Environment \& Planning C: Government \& Policy (in press).

Jakeman, A. J. and Letcher, R. A. (2003) Integrated assessment and modelling: Features, principles and examples for catchment management. Environmental Modelling and Software 18(6), 491-501.

Jakeman, A.J., et al. (2006) Integrated modelling: construction, selection, uncertainty. In: Sustainable Management of Water Resources: an Integrated Approach (ed. by C. Giupponi, et al.) Edward Elgar Publishing, Cheltenham, UK

Jakeman, A.J., et al. (eds) (2014) Modelling for managing the complex issue of catchment-scale surface and groundwater allocation. In: Simulation and Modeling Methodologies, Technologies and Applications (ed. ), Springer, 25-41..

Letcher, R.A., Croke, B.F.W., Jakeman, A.J. and Merritt, W.S. (2006a) An integrated modelling toolbox for water resources assessment and management in highland catchments: Model description. Agricultural Systems, 89, $106-131$.

Letcher, R.A., et al. (2006b) An integrated modelling toolbox for water resources assessment and management in highland catchments: Sensitivity analysis and testing. Agricultural Systems 89, 132-164.

Montanari, A., et al:: Panta Rhei - Everything Flows: Change in hydrology and society - The IAHS Scientific Decade, 20132022. Hydrol. Sci. J. 58, 1256-1275, doi:10.1080/02626667.2013.809088, 2013.

Offermans, A. and Cörvers, R. (2012) Learning from the past; changing perspectives on river management in the Netherlands. Environmental Science \& Policy 15(1), 13-22.

Ostrom, E. (2009) A general framework for analyzing sustainability of social-ecological systems. Science 325, 419-422.

Pahl-Wostl, C., et al. (2008) The importance of social learning and culture for sustainable water management. Ecological Economics 64(3), 484-495.

Poff, N. L., et al. (1997) The natural flow regime. BioScience 47, 769-784.

Pohl, C. (2008) From science to policy through transdisciplinary research. Environmental Science \& Policy 11(1), 46-53.

Rogers, P. and Hall, A. (2003) Effective Water Governance. Global Water Partnership Technical Committee, Background Paper no. 7.

Sivapalan, M., Savenije, H. H. and Blöschl, G. (2012) Socio-hydrology: a new science of people and water. Hydrol. Processes 26, 1270-1276, doi:10.1002/hyp.8426, 2012. 